\title{
ANALISIS AKSESIBILITAS PETANI PERKOTAAN TERHADAP AGROINPUT DAN IMPLIKASINYA TERHADAP PENGEMBANGAN URBAN FARMING
}

\author{
Harniati, Reni Suryanti \\ Sekolah Tinggi Penyuluhan Pertanian Bogor \\ Corr: tatie.hr@gmail.com, reni.suryanti_spt@yahoo.com
}

\begin{abstract}
ABSTRAK
Urban Farming kian berkembang dan potensial menjadi bagian dari solusi atas permasalahan pangan bagi penduduk perkotaan. Namun, fasilitasi dan pengembangannya belum mampu mengatasi permasalahan dan tekanan yang dihadapi petani perkotaan utamanya aksesibilitas petani terhadap agroinput. Tujuan penelitian adalah 1) mengidentifikasi permasalahan agroinput 2) mengetahui akses petani terhadap agroinput, 3) menganalisis implikasi kebijakan terhadap pengembangan urban farming. Penelitian menggunakan pendekatan survey dengan metoda deskriptif analitis dan metoda kuantitatif menggunakanskala Likert. Responden adalah anggota kelompoktani agribisnis padi sawah, pengolahan hasil, dan agribisnis ternak domba. Responden berjumlah 40 orang yang merupakan petani pada kelompoktani dan gabungan kelompoktani pada intra-urban (Situ Gede, Margajaya) dan periurban (Pasir Buncir, Pasir Eurih) yang ditentukan secara purposive stratified random sampling. Variabel agroinput yang diamati adalah lahan, air, bibit/benih, pupuk, obat-obatan, teknologi, serta tenaga kerja. Hasil penelitian menunjukkan bahwa agroinput yang sulit diakses petani adalah lahan, tenaga kerja, benih, pupuk dan konsentrat pakan. Kepemilikan lahan padi sawah di daerah peri urban adalah kurang dari $0,2 \mathrm{Ha}$ dan pada daerah intra urban tidak memiliki lahan. Tenaga kerja dari luar sulit diakses, karena keterbatasan dalam ketersediaan dan upah relatif mahal. Pada agribisnis ternak domba, konsentrat jarang tersedia dan sulit diakses karena harga yang mahal. Keterbatasan aksesibilitas terhadap agroinput berimplikasi pada perubahan model atau pola pengembangan agribisnis spesifik perkotaan, fasilitasi, kelembagaan dan regulasi dalam pengembangannya.
\end{abstract}

Kata Kunci: aksesibilitas, agroinput, urban farming.

\begin{abstract}
Urban Farming is growing rapidly and becoming as a part of the solution for food insecurity and malnutrition problems of urban citizen. But, the facilitation and development of urban farming have not been able to overcome problems and pressure faced by urban farmers mainly accessibility to agroinput yet. Objectives of this research were to 1) identify the problems of agroinput, 2) to know accessibility of farmer to agroinput, 3) to analyze the policy implication to the development of urban farming. The research used an explanatory survey method. Sampling method used waspurposive stratified random sampling. Availability of agroinput and farmer's accessibility were quantified using Likert's Scale. Respondents were member of farmer's group of paddy agribusiness, sheep, and processing of agriculture products. This research was conducted in the villages of Situ Gede and Margajaya for intra-urban, and Pasir Buncir and Pasir Eurih of Tamansari for peri-urban.The observed variables are land, water, seeds/seedlings, fertilizers, pesticides, technologyas well as labor.Results of the study:1) agroinput that are difficult to access by farmers are land, labor, feed concentrate, fertilizer, and seed.Paddy land ownership in peri-urban is less than $0.2 \mathrm{Ha}$ and in intra-urban areas are landless farmers. Outside labor is difficult to access because of itslimited amount or availibility and the wages is relatively expensive. Feed concentrate for sheep rarely available and not affordable because it's expensive. Limited accessibility to agroinput for urban agribusiness and its problems and challenge will bring changing policy implication for developing urban farming, mainly for facilitation, development of urban agribusiness model, empowering institusional, and regulatory.
\end{abstract}

Key Words: accessibility, agroinput, urban farming. 


\section{PENDAHULUAN}

Lebih dari satu dasawarsa pertanian perkotaan (urban farming) berkembang begitu pesat di banyak kota di dunia, seiring dengan timbulnya berbagai permasalahan yang khas perkotaan; antara lain kerawanan pangan, malnutrisi, kemiskinan dan isu lingkungan. Peran urban farming dalam konteks peningkatan pendapatan, akses pangan, isu lingkungan dan kesehatan diyakini sebagai bagian dari solusi permasalahan perkotaan yang merupakan akumulasi dari dampak arus urbanisasi (FAO, 2007). Urban Farmingdidefinisikanoleh FAO(1999)sebagai sebuah industriyangmemproduksi,memproses, da nmemasarkanproduk danbahan bakarnabati,terutamadalammenanggapipe rmintaanhariankonsumendi dalam perkotaan, yang menerapkan metode produksi intensif, memanfaatkan dan mendaur ulangsumberdayadanlimbah perkotaanuntuk

menghasilkanberagamtanamandan

hewanternak.Yang dimaksud dengan perkotaan yaitu wilayah intra-urban dan peri-urban; yakni wilayah dalam kota dan daerah pinggirannya yang nuansa dan pola kehidupannya relatif sama dengan di dalam kota. Beberapa kota di dunia sudah sukses mengembangkan urban farming untuk meningkatkan pendapatan penduduknya, juga berkaitan dengan peningkatan kesejahteraan melalui kesehatan, perbaikan lingkungan dan amenity/fasilitas perkotaan serta mengatasi kerawanan pangan. Potensi dan

manfaatpengembanganpertanianperkotaa ncukupbesar, kehadirannyabelumbanyakdisadaridanbel umsepenuhnyadidukungdengan

kebijakanyangmemadai.Halinidiantaranya dapatdilihat darikeberlanjutanpertanian kotayangmasihrendahyaknipadaindekskur angberlanjut(Sampelilingetal.,2012).

Danpadabeberapakota

keberlanjutanpertanianperkotaanterus menurunseiringdengan

perubahanalokasipenggunaanlahanpertani andidaerahpinggirankota(Sudirmanet.al,2 010).Kebijakan, termasuk fasilitasi untuk pertanian di perkotaan kurang mendapat perhatian, selain itu, juga kurang sesuai dengan kebutuhan, permasalahan dan peluang serta potensi yang ada di perkotaan; dan yang relatif berbeda dengan perdesaan. Tantangan terbesar yang dihadapi petani; termasuk peternak di perkotaan adalah masalah agroinput atau input produksi.

Agroinput merupakan salah satu subsistem dalam sistem agribisnis. David and Goldberg (1957) mendefinisikan agribisnis sebagai "The sum total of all operations involved in the manufacturer and distribution of farm supplies; production operations on the farm, processing and distribution of farm commodities and items made for them". Dengan demikian, kegiatan agribisnis tidak hanya kegiatan budidaya atau onfarm operation saja. Krisnamurthi dan Pambudy (2010) menyebutkan bahwa pembangunan pertanian dengan paradigma agribisnis menghendaki adanya keterkaitan sistem produksi dengan pendukung yang efisien yaitu (a) penyediaan input produksi (lahan, air, benih, pupuk, pestisida, dan tenaga kerja, (b) perbankan dan asuransi, (c) industri pengolahan,

(d) pengembangan 
teknologi untuk meningkatkan nilai tambah, (e) transportasi. Selanjutnya, Saragih (2001) menyebutkan bahwa sistem agribisnis terdiri dari 4(empat) subsistem yakni (a) subsistem agribisnis hulu (upstream agribusiness) yakni kegiatan ekonomi yang menghasilkan sarana produksi pertanian seperti industri pembibitan/perbenihan, industri agrokimia, industri agro-otomotif; (b) subsektor pertanian primer (on-farm agribusiness) yakni kegiatan ekonomi yang menggunakan sarana produksi pertanian untuk menghasilkan komoditi pertanian primer; (c) subsektor agribisnis hilir (downstream agribusiness)yakni kegiatan ekonomi yang mengolah komoditas pertanian primer menjadi produk-produk olahan baik berupa produk antara (intermediate product) maupun produk akhir (final product) beserta kegiatan perdagangannya; (d) subsektor jasa penunjang (supporting institution) yakni kegiatan yang menghasilkan jasa yang dibutuhkan seperti perbankan, transportasi, penelitian dan pengembangan, kebijakan pemerintah, penyuluhan dan konsultan, dan lain-lain. Dengan demikian, dapat dikatakan bahwa subsistem agroinput merupakan bagian yang penting dan sangat menentukan khususnya dalam menghasilkan produk primer, dan juga sebagai produk utama dari subsektor agribisnis hulu.

Kebijakan dan fasilitasi untukpengembanganpertanianperkotaanse harusnya berbeda dengan pertanian yangumumdilakukan diperdesaan; baik pada subsistem agroinput, subsistem produksi, juga subsistem-subsistem lainnya.
Dinamikasosialekonomipendudukperkota an dengan ragam permasalahan, tantangan, dan peluang membawakonsekuensi kebijakan pengembangan yang berbeda.Subsistemsubsistem ini berkaitan erat bahkan sebagai satu kesatuan sistem; sehingga pengabaian terhadap subsistem agroinput akan membawa dampak tidak baik terhadap keseluruhan sistem agribisnis khususnya urban farming. Permasalahan pada agroinput antara lain dapat diidentifikasi melalui aksesibilitas petani atau pelaku agribisnis terhadap agroinput.

Sehubungandenganhaltersebut,peneli tianini bertujuanuntuk1) mengidentifikasi permasalahan agroinput 2) mengetahui akses petani terhadap agroinput, 3) menganalisis implikasi kebijakan terhadappengembangan urban farming.

\section{METODE}

Aksesibilitas petani terhadap agroinput dalam penelitian ini didefinisikan sebagai tingkat atau derajat (1) ketersediaan agroinput dan (2) keterjangkauan oleh petani. Baik ketersediaan maupun keterjangkauan dikuantifikasi dengan menggunakan skala Likert. Variabel ketersediaan yaitu 1) Tepat jenis, 2) Tepat waktu, 3) Tepat tempat, 4) Tepat mutu, 5) Tepat jumlah. Variabel keterjangkauan yaitu harga. Agroinput yang dianalisis dalam penelitian ini yaitu lahan, air, benih/bibit, pupuk, konsentrat dan hijauan makanan ternak, obat-obatan, teknologi dan tenaga kerja.

Penelitian ini dirancangsebagaipenelitiandeskriptifekpla natoriuntuk menjelaskan aksesibilitas 
petani perkotaan terhadap agroinput dilokasipenelitian.Penelitian menggunakan pendekatan survey dengan metoda deskriptif analitis dan metoda kuantitatif mengunakanskala Likert.

Penelitian dilaksanakan pada bulan Oktober sampai dengan Desember 2014. Responden penelitian berjumlah 40 orang yang merupakan petani di daerah intraurban danperi-urban yang mewakili usahatani yang homogen pada kelompok terpilih. Penentuan jumlah responden dengan menggunakan persentasi dari total jumlah petani pada kelompoktani terpilih di lokasi penelitian.

Penentuanlokasi

penelitiandilakukanmenggunakanpendekat anpurposivestratified

randomsampling.Penelitiandilakukandi

kota Bogorsebagai intra urbandanwilayah pinggiran

kotaBogorsebagaiperiurban.Pemilihan wilayahintra urbandidasarkanpadastudiawalpenelitian mengenai potensipertaniandimasingmasing

kecamatandiKotaBogor.Berdasarkanwawa ncara dengankeypersondariDinas

PertanianKota BogordanKantorKetahanan PanganKotaBogorrmakaditetapkanlokasip enelitianuntukwilayahintraurbanadalahKe lurahan SituGededanKelurahanMargajaya KecamatanBogorBarat.Sedangkan

penentuan lokasi untukwilayahperiurbandilakukandenganm emilihdaerahpinggirankota Bogor yangmasih

bernuansaurban,mengacupadadefinisi

FAO,memilikipotensisektor pertaniansertamemilikikomoditi pertaniantertentu.Berdasarkankriteriaterse but,dipilih DesaPasirEurih dan DesaPasirBuncirdiKecamatanCaringin.Dis tribusi responden dan lokasi penelitian dapat dilihat pada Tabel1.

Tabel 1. Distribusi responden penelitian

\begin{tabular}{|c|c|c|c|c|}
\hline $\begin{array}{l}\text { Wilayah, } \\
\text { Kecamatan }\end{array}$ & $\begin{array}{c}\text { Kelurahan/ } \\
\text { Desa }\end{array}$ & Komoditas & Kelompoktani & $\begin{array}{l}\text { Responden } \\
\text { (orang) }\end{array}$ \\
\hline \multicolumn{5}{|l|}{ Intra Urban } \\
\hline \multirow[t]{3}{*}{ Kec. Bogor Barat } & Situ Gede & Padi, TalasOlahan & Delima & 5 \\
\hline & & & Sawargi & 5 \\
\hline & Margajaya & Padi & Fajar Gumbira & 10 \\
\hline \multicolumn{5}{|l|}{ Peri Urban } \\
\hline Kec. Caringin & Pasir Buncir & Domba & Bersaudara & 10 \\
\hline Kec. Tamansari & Pasir Eurih & $\begin{array}{l}\text { Tanaman pangan, } \\
\text { sayuran }\end{array}$ & Karya Tani & 10 \\
\hline Jumlah responden & & & & 40 \\
\hline
\end{tabular}

Jenisdatayangdigunakandalampeneli Dataprimerdiperolehdariwawancaraterstru tianiniadalahdataprimerdandatasekunder. kturdenganpetanidanpenyuluh. Data 
sekunderyangdihimpunberupahasilpenelit ian,statistik,laporandan dokumentasiyang berkaitandengantujuan

penelitian.Instrumentataualatyangdigunak andalampenelitian

iniadalahkuisionerdanpanduanwawancara .Pengumpulandatadilakukandengan metodesurvei.

Analisis data yang digunakan untuk menjawab tujuan pertama penelitian yaitu:

1. Analisis deskriptif: digunakan untuk mengidentifikasi permasalahan agroinput pada urban farming

2. Analisis kuantitatif menggunakan skala Likert untuk mengukur aksesibilitas petani terhadap agroinput.

Variabel agroinput yang diamati adalah lahan, air, bibit/benih, pupuk, obat-obatan, teknologi, peralatan dan mesin, serta tenaga kerja. Variabelvariabel tersebut dilihat dari ketersediannya dan keterjangkun oleh petani. Variabel-variabel tersebut dihitung dengan menggunakan teknik scoring Skala Likert. Setiap pernyataan dalam kuisioner terdiri dari lima pilihan jawaban yang dinilai dengan nilai terendah satu dan nilai tertinggi lima.

Nilai lima untuk variabel lahan apabila lahan tersedia dalam jumlah yang memadai, kontinyu dalam penggunaan dan dapat diakses petani. Nilai tertinggi untuk variabel pengairan adalah bila pengairan mengggunakan irigasi teknis, air mengalir sepanjang waktu dan biaya pengairan murah. Nilai tertinggi untuk variabel teknologi bila petani telah dapat menggunakan teknologi modern termasuk teknologi yang berhubungan dengan urban farming serta mampu mengakses teknologi. Variabel ternak diberi nilai tertinggi bila petani memilki dan memelihara ternak dalam jumlah yang memenuhi skala usaha. Variabel tenaga kerja dinilai tinggi dengan skor lima bila tenaga kerja tersedia dalam jumlah memadai danupahnya terjangkau oleh petani. Variabel pupuk, obatobatan,benih, bibit ternak, pakan, konsentrat dan bahan baku olahan dikatakan memiliki skor tinggi bila ketersediaan saprodi tersebut kontinyu dan memenuhi lima tepat (tepat jumlah, waktu, harga, jenis dan mutu), serta dapat diakses petani dengan mudah.

Interpretasi data dilakukan setelah data diolah dengan perhitungan skor dengan pendekatan skala Likert. Total skor merupakan perkalian dari jumlah responden yang menjawab, jumlah butir pertanyaan dan skor masing-masing jawaban. Total skor dibandingkan dengan skor tertinggi untuk mendapatkan presentase jawaban responden. Persentase jawaban tersebut diinterpretasikan dengan kriteria sangat rendah/ kurang sekali, rendah/kurang baik, cukup/netral, baik, sangat baik.

\section{HASIL DAN PEMBAHASAN}

Sub sistem agroinput merupakan salah satu sub sistem yang membentuk sistem agribisnis yang secara langsung akan mempengaruhi baik buruknya kinerja sistem agribisnis tersebut. Pada pertanian perkotaan, lahan merupakan salah satu agroinput pembatas disamping agroinput lainnya. Keterbatasan agroinput khususnya lahan pertanian di perkotaan dapat diatasi dengan mengadopsi konsep 
atau paradigma agribisnis. Dengan konsep agribisnis, petani mampu memaksimalkan pendapatannya dalam keterbatasan yang ada. Menurut Saragih (2001) agribisnis tidak hanya proses produksi on-farm, tetapi meliputi produksi dan jasa pada industri hulu dan juga pada industri hilir. Gambaran tentang keterkaitan subsistem agroinput dalam agribisnis pertanian perkotaan dapat dilihat pada Gambar 1.

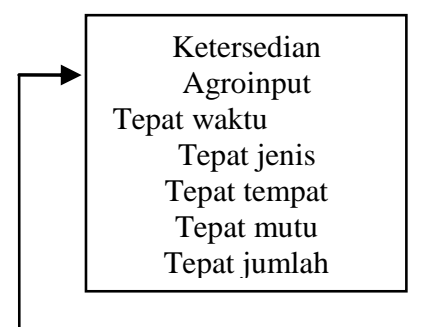

Gambar 1. Faktor yang mempengaruhi aksesibilitas agroinput

Hasil penelitian menunjukkan bahwa terdapat keterbatasan petani terhadap akses lahan. Permasalahan lahan pada umumnya adalah petaniintra urban tidak memiliki lahan, dan petani peri urban memiliki lahan terbatas yakni kurang dari $0.2 \mathrm{Ha}$ per rumah tangga pertani. Selain itu, petani mengusahakan lahan baik milik sendiri ataupun sewa/sakap juga terbatas luasnya sehingga belum memenuhi skala ekonomi yang didefinisikan sekitar $4 \mathrm{Ha}$ untuk komoditas padi sawah. Secara umum, agroinput yang sulit diakses petani ialah lahan, tenaga kerja, benih, pupuk dan konsentrat pakan ternak. Skala Likert menunjukkan bahwa aksesibilitas petani peri-urban dan intra-urban dalam mengakses lahan adalah skala 2 dengan kemampuan aksesibilitas 20\% hingga $39 \%$; sehingga dapat dikatakan kondisi
Kurang Baik. Semua variabel ketersediaan dan keterjangkauan lahan menunjukkan kondisi kategori Kurang Baik.

Kondisi yang sama juga ditunjukkan oleh tingkat kedua atau pada skala 2 pada Skala Likert; artinya bahwa aksesibilitas petani terhadap teknologi, tenaga kerja, benih, pupuk dan konsentrat Kurang Baik. Teknologi yang diterapkan petani masih berbasis lahan, dan belum menerapkan teknologi pertanian untuk lahan sempit perkotaan. Penawaran tenaga kerja terbatas, dan tidak selalu tersedia pada waktu yang dibutuhkan, dan upah harian tenaga kerja reatif mahal bagi petani. Benih yang digunakan petani adalah benih derivat/turunan produksi petani dan sebagian besar tidak bersertifikasi. Petani menggunakan benih produksi petani tersebut dikarenakan 
mahalnya benih yang bersertifikat; meskipun ketersediaannya cukup baik di perkotaan. Ketersediaan pupuk menjadi masalah bagi petani. Dari sisi ketersediaan, pupuk jarang sekali tersedia tepat waktu, sering terjadi kelangkaan, Selain itu, pupuk yang ada jenisnya bukanlah yang dibutuhkan petani, tetapi petani harus mengolah atau mencampur lagi. Keterjangkauan petani terhadap pupuk juga rendah atau kurang baik karena mahalnya harga pupuk, apalagi setelah pupuk tidak disubsidi oleh pemerintah. Dengan kata lain, ketersediaan pupuk dan keterjangkauan petani terhadap pupuk kurang baik; secara keseluruhan aksesibilitas petani terhadap pupuk Rendah. Konsentrat pakan ternak kurang terjangkau oleh peternak karena harganya yang mahal. Selain itu, konsentrat tidak selalu tersedia pada waktu, tempat dan jenis yang dibutuhkan peternak. Secara umum, peternak sangat jarang menggunakan konsentrat berlabel terutama karena faktor keterjangkauan harga dan faktor ketersediaannya.

Agroinput lainnya yaitu sumber air, bibit ternak, obat-obatan, hijauan makanan ternak dan bahan baku untuk industri pengolahan hasil pertanian khususnya talas berada pada tingkat 3 pada Skala Likert. Kondisi ini menunjukkan kondisi yang moderat, atau Cukup; tidak terlalu sulit, tetapi juga tidak terlalu mudah.

Kondisi lapanganpadawilayahperiurbandanurban menunjukkanprofil yang hampirsamadarisisikarakteristikpetani.Ma yoritaspetani (40\%)berusiadi atas55 tahun.Tingkatpendidikanpetanididesaperi -urbandandesaurban menunjukkanhal yanghampir sama kondisinya; yakni mayoritas atausekitar $60 \%$ berpendidikan tidak tamat SDdan tamat SD. Petaniperiurbanpadaumumnyabekerjajugadiluarsekt orpertaniandisampingberusahatani.Data menunjukkanbahwa75\% petaniperi-urban bekerjasampingansebagaiburuh industri, buruhbangunan,berjualan, jasacleaning servicedansebagainya. Penelitan ini mendapatibahwa

menjadipetanibukanlahpilihan

utamaparapetani;dengankata

lain, menjadipetanibukankarenakeinginan menjadi enterpreneurdibidangpertanian, tetapi karenaketerbatasan lapanganpekerjaan formal dipadudengankondisipetani yang unskilled labor/tidak berketerampilan lain. Kondisi yangberbedaditunjukkan olehpetaniurban, dimana55\%diantaranya tidak mempunyaipekerjaansambilan; jadi hanya

menggantungkannafkahkeluarganyapadah asil usahatani. Penghasilandari berusahatani lebih kecildaripadaUpah Minimum Regional (UMR)kota Bogor.

Karakteristikusahatanidiwakili

olehkondisikepemilikan lahan yang relatifkecil atau tidak memiliki lahan,danusahataniberbasis lahan. Sebagiankecilpetani memiliki lahan,namun luasnya rata-rata tidak lebihdari2000 m2. Belumditemuipetani yang memanfaatkansecaraoptimal lahanpekarangan ataupun lahan tidur. Pada umumnya, jika tidak memiliki lahanuntukpertanian,pilihanpetani adalah menyewa lahan ataupun menggarap lahanorang laindengansistim bagihasil. Lahan yangdigarap petaniumumnya terpencar. Lahanpertanian yangdigarapolehparapetanipenggarap 
padaumumnyadimilikioleh orangdari luardesa lokasipetani.

Agroinput khususnya lahan di perkotaan sangat rawan menjadi lahan non pertanian atau sangat rawan terhadapalih fungsilahankarenalahan disekitarnya sudah menjadi pemukiman atau pembangunan lainnya.Kecenderungan alih fungsilahan ini sangat tinggi, karenaopportunity cost untuk menjadikan lahan usahatani sangat tinggi dengan tingginya permintaan (demand) terhadap lahan untuk permukiman yang selanjutnya memicu melambungnya harga tanah eks lahan pertanian. Petani tidak punya bargaining positition/posisi

tawardalam mengusahakan lahan karena lahan bukan miliknya; dan bergantung pada keputusan pemilik lahan. Pemilihan komoditas yang diusahakan petani masih berdasarkan kebutuhan pangan keluarga; belum berorientasi pasar atau belum menjadikan pasarsebagaibahan pertimbanganutama.

Secarakeseluruhanusahatanidi desadesatersebutbelum 'marketdriven'.

Agroinput lainnya yakni teknologi khas perkotaan selain teknologi untuk lahan sempit juga dicirikan oleh pemilihan komoditas yang bernilai ekonomi tinggi dan dengan permintaan (demand) yang tinggi. Selanjutnya, agroinput tenaga kerja terampil menjadi sesuatu yang sulit diperoleh dikarenakan tenaga kerja terampil khususnya di perkotaan akan diserap oleh sektor industri ataupun sektor non pertanian lainnya, karena upah yang lebih tinggi. Penelitian Harniati dan Reni (2014) melaporkan bahwa pertanian dan peternakan di kota Bogor dan Kabupaten
Bogor memberikan pendapatan yang lebih rendah daripada Upah Minimum Regional kota Bogor dan Kabupaten Bogor.

\section{SIMPULAN DAN SARAN}

\section{Simpulan}

Petani urban/perkotaan menghadapi permasalahan agroinput utamanya adalah lahan, tenaga kerja, teknologi, benih, pupuk, dan konsentrat pakan ternak. Aksesibilitas petani terhadap agroinput ditunjukkan oleh tingkat yang rendah atau kondisi Kurang Baik pada skala Likert.

Agroinput bibit, hijauan makanan ternak, sumber air/pengairan dan bahan bakuolahan hasil menunjukkan aksesibilitas moderat atau kondisi Cukup (tingkat 3 Skala Likert).

\section{Saran}

Kebijakan pengembangan urbanfarming/pertanian perkotaan seyogyanya tidak disamakan dengan kebijakan pengembangan pertanian perdesaan; karena permasalahan agroinput dan aksesibilitas petani terhadap agroinput berbeda dengan perkotaan. Diperlukan regulasi dan kajian lebih lanjut untuk merumuskan model atau pola pengembangan urban farming.Regulasi pemerintah yang utama untuk mengatasi permasalahan mendasar lahan produktif yaitureformasiagraria. Regulasi undangundanglahan abadidanregulasilahanlahanyangdilindungiuntuk

lahanpertanianberkelanjutan perlu dikawal implementasinya.Selanjutnya, diperlukankebijakanagarmemberikan fasilitasibagipetaniuntuk menggarap 
lahan-lahan tidur,mengembangkanlahanlahan marjinaldan infrastrukturyang dibutuhkan industri pertaniansepertikelembagaanpermodaland anpasarbagiproduk pertanian. Agar dapat merumuskan solusi dalam mendorong pertanian di lahan sempit di perkotaan, diperlukanpenelitian lanjutan untuk mengetahuifaktor-faktorpendorong dan penghambat tumbuh kembangnya pertanian perkotaan dan akses petani atau pengusaha tani terhadap agroinput. Dengan demikian sekaligus akan diperolehpemecahanmasalahpertanianperk otaandenganpendekatanspatial economy.

DAFTAR PUSTAKA

BPS. 2013. KotaBogorDalamAngka. BPSKotaBogor.

FAO,2007.ProfitabilityandSustainabilit yofUrbanandPeri-

UrbanAgriculture.Rome :Food and AgricultureOrganization oftheUnitedNations.

FAO.2011.The PlaceofUrbanandPeriUrbanAgriculture(UPA)in NationalFood Security

Programmes.Integrated Food SecuritySupportService(TCSF) Policy and ProgrammeDevelopmentSupportD ivision TechnicalCooperation Department.

Harniati, Suryanti,R 2014. Profil dan Profitabilitas Pertanian
Perkotaan. Laporan Penelitian Sekolah Tinggi Penyuluhan Pertanian Bogor.

Krisnamurthi B, Pambudy R, Dabukke F, 2015. Refleksi Agribisnis 65 Tahun Profesor Bungaran Saragih.Bogor : IPB Press.

Sampeliling

S.,Sitorus, S.,Nurisyah,S.,Pramudy a,Bambang.2012.Kebijakan

PengembanganPertanianKotaB erkelanjutan:Studi

KasusdiDKIJakarta. Analisis KebijakanPertanian.Bogor :Pusat Studi danKebijakan Pembangunan Pertanian.Volume10 No3.

Saragih, Bungaran. 2000. Agribisnis Berbasis Peternakan.Bogor :PT Loji Grafika Griya Sarana. 2001. Agribisnis Paradigma Baru Pembangunan Ekonomi Berbasis Pertanian.Bogor :PT Loji Grafika Griya Sarana.

2001. Suara Dari Bogor. Membangun Sistem Agribisnis.Bogor: PT Loji Grafika Griya Sarana.

Soekartawi, 1995. AnalisisUsahaTani.

Sudirman,S.

Irham.Hartono,Slamet.Maas,Azw ar.2010.AnalisisFaktorPenyebab dan Dampak 
